\title{
CLASSIFICAÇÃO DE MONTANHAS PELA ALTURA
}

\author{
Antonio Paulo Faria \\ Professor Adjunto - IGEO/UFRJ \\ antoniofaria15@terra.com.br - antoniofaria15@hotmail.com
}

\begin{abstract}
Resumo
Existem algumas formas para definir montanhas e classificá-las em classes de tamanho em função de alguns parâmetros: altura, altitude e zona alpina. Neste trabalho é sugerida uma classificação baseada no relevo relativo (altura) que define o seguinte: montanhas baixas têm entre 300 e $1.000 \mathrm{~m}$ de altura, as médias entre 1.000 e $3.000 \mathrm{~m}$ e as altas, acima de $3.000 \mathrm{~m}$ de altura. Os dados mostram que o Dhaulagiri $(8.167 \mathrm{~m})$ pode ser a montanha mais alta da Terra, cuja altura chega a $5.700 \mathrm{~m}$, enquanto o Everest $(8.850 \mathrm{~m})$ possui uma altura modesta, de $3.200 \mathrm{~m}$. As maiores montanhas brasileiras têm altura de aproximadamente $1.800 \mathrm{~m}$ e extensão das vertentes com cerca de $4.000 \mathrm{~m}$ e as maiores escarpas rochosas no país têm entre $700 \mathrm{e} 1.000 \mathrm{~m}$ de altura.
\end{abstract}

Palavras-chave: Montanhas; Alturas; Classificação; Escarpas.

\begin{abstract}
There are different ways to define mountains and create classifications according to the size due to parameters, like: height, altitude, and snow line. In this work a classification based on local relief is suggested which defines: low mountains (300 - 1000 $\mathrm{m}$ in height), medium mountains $(1.000-3000 \mathrm{~m})$, and high mountains (above $3.000 \mathrm{~m})$. According to the data, Dhaulagiri $(8.167$ $\mathrm{m})$ could be the highest mountain on Earth, because its height reaches $5.700 \mathrm{~m}$, while Everest $(8.850 \mathrm{~m})$ is a modest $3.200 \mathrm{~m}$ in height. The largest Brazilian mountains have heights around $1.800 \mathrm{~m}$ and their slopes can reach $4.000 \mathrm{~m}$ in length with the highest free faces having heights in between 700 and $1.000 \mathrm{~m}$.
\end{abstract}

Key Words: Mountains; Height; Classification; Free fall faces.

\section{Introdução}

As pessoas leigas fazem confusão quando falam em colina, morro, pico, montanha, monte, serra, etc. Existem algumas formas para classificar relevo: em função da origem, a exemplo de Fairbridge (1968); pode ser do ponto de vista estético; pela altura/altitude e pela forma. King (1967) elaborou uma classificação que leva em conta apenas as montanhas produzidas nos cinturões orogenéticos, deixando todos os outros tipos de fora. Baseados nessa classificação, ou não, alguns geólogos e geógrafos dizem que não existem montanhas no Brasil, o que é um grande erro, porque pensam que só existem montanhas em cinturões orogenéticos ativos. Como este processo é considerado extinto no país, portanto, segundo eles, não existiriam montanhas. Porém, eles nem sempre consideram que em zonas de divergência de placas também são produzidas cadeias de montanhas pelo processo epirogenético e ainda existem diversos tipos de montanhas produzidos por outros processos.

Muitas vezes não há consenso em relação a tais classificações porque cada profissional pode ter um objetivo específico e as próprias definições para montanhas e morros em alguns dicionários não são precisas. Para um simples observador ou mesmo para os montanhistas, pode parecer simples identificar uma montanha na paisagem porque eles possuem um objetivo claro e específico. Por exemplo, em áreas planas, uma elevação isolada de $200 \mathrm{~m}$ de altura se destaca na paisagem e isso pode influenciar uma percepção distorcida aos olhos de um observador não treinado. De fato, isso pode superestimar a sensibilidade humana devido à falta de um referencial, o que não ocorre normalmente numa região acidentada. Para os índios brasileiros da nação Tupi, que habitavam uma boa parte das áreas montanhosas do Sudeste, não existia uma distinção entre morro e montanha, tudo era "ita" quando a rocha aflorava, de acordo com Faria (2005). Se de um lado classificar montanhas do ponto de vista popular passa pela percepção que o observador tem, quando se tenta classificá-las tecnicamente, podem surgir algumas dificuldades.

Para a geomorfologia, em geral considera-se montanha como uma elevação cuja altura em relação à base é maior que 300 metros e com vertentes de inclinação acentuada. Sendo assim, a elevação precisa estar a pelo menos 300 metros acima do relevo médio circundante. Esta é a forma mais simples 
para classificar montanhas, de acordo com Bates \& Jackson (1976) e Price (1981). Porém, não é definido qual é a declividade mínima das vertentes. As elevações que estiverem abaixo deste limite podem ser consideradas morros ou, se for o caso, planícies, planaltos, altiplanos e platôs. O Dicionário Geológico-Geomorfológico de autoria de Guerra (1993), define da seguinte forma: "MONTANHA - grande elevação natural do terreno com altitude superior a 300 metros e constituída por um grupo de morros..." a palavra certa é altura. O mesmo ocorreu na definição de morro. Por exemplo, o Pico das Agulhas Negras tem 2.789 de altitude, mas sua altura fica em torno de 489 metros, porque a base está no platô de Itatiaia, que se situa aproximadamente a $2.300 \mathrm{~m}$ de altitude. A altitude está sempre relacionada ao nível do mar e ela não serve para definir montanha, muito menos se ela é alta ou baixa. No Chile, na Bolívia e no Peru existem extensos platôs cujas altitudes ficam entre 3.000 e 4.000 metros, como exemplo o Altiplano Boliviano. O Platô Tibetano, na Ásia, tem altitudes em torno de 5.000 metros e sobre ele assentam-se muitas das maiores montanhas do planeta.

No Brasil existem as serras (blocos continentais falhados) que possuem escarpas íngremes com desnível vertical de até $1000 \mathrm{~m}$, porém, elas não são montanhas. A Serra Geral, por exemplo, pode ser descrita como um imenso platô com a borda atlântica com escarpas muito acentuadas onde foram esculpidas muitas montanhas. Situação parecida ocorre na Serra do Mar e na Serra da Mantiqueira, entre outras, mas nessas, o histórico tectônico e litológico deram condições para formar um número maior de montanhas, em suas bordas e em seus reversos.

De acordo com Gerrard (1990), muitos pesquisadores que trabalham em áreas montanhosas concordam que o relevo relativo deve ter desnível vertical maior que 300 metros, mas em se tratando de geoecologia, um consenso parece apontar que o limite de 700 metros é mais realístico, quando o clima e a vegetação mudam sensivelmente. Porém, esse é um objetivo puramente geoecológico.

A forma das elevações (morfologia) pode auxiliar na definição de morros e montanhas, principalmente para distinguílas dos platôs e serras. Por exemplo, existem morros e montanhas em forma de hogback e uma das montanhas mais famosas com essa forma é o Monte Rundle (2.949 m) no Canadá, cuja altura (relevo relativo) é de $1.554 \mathrm{~m}$. Sendo assim, podemos encontrar morros e montanhas com a mesma morfologia. Em se tratando de sequências monoclinais sedimentares, temos formas como: cuesta, hogback, dogtooth, matterhorn (torre semi-piramidal), castellate (castelo), mesa, torre e pirâmide (com 3 ou 4 faces) como indicam Cruden \& Hu (1999). Em dobras simples, são comuns os anticlinais e anticlinais suspensos, mas ainda existem formas indefinidas esculpidas em dobramentos complexos. Em se tratando de rochas ígneas, em áreas glaciais ou mesmo em outras áreas onde a ação do intemperismo físico é intensa, são comuns montanhas e morros em forma de torres e agulhas. Em algumas áreas elas também ocorrem em forma de domo. No Brasil, uma forma muito comum são os pontões esculpidos em rochas ígneas metamórficas, que a geomorfologia clássica denominou de pão-de-açúcar. Faria (2004a) disserta que existem morros e montanhas com esta forma, a exemplo do próprio Pão de Açúcar, no Rio de Janeiro, que é uma montanha de 392 metros de altitude e também de altura, porque a base fica ao nível do mar.

Sendo assim, para classificar uma montanha deve ser levado em conta o relevo relativo, a declividade do terreno e também a morfologia. Porém, se a definição de montanha é bem clara, o mesmo não ocorre quando se tenta classificálas em: baixas, médias e altas, e este é o objetivo deste trabalho, que sugere uma classificação.

\section{Algumas considerações sobre a altura das montanhas}

Para classificar montanhas baixas, médias e altas vai depender do objetivo. Profissionais de áreas distintas criaram as suas próprias classificações para atender suas necessidades. Pode ser em função de interesse biológico; pode ser visando os efeitos que a altitude causa na população humana, em especial nos montanhistas; ou pode ser uma classificação geomorfológica.

\subsection{Geomorfologia}

Montgomery \& Greeberg (2000) e Brocklehurst \& Whipple (2004), dissertam que a altura dos picos é possivelmente $\mathrm{o}$ aspecto geomorfológico mais proeminente em uma cadeia de montanha. A tectônica e os processos erosivos geralmente influenciam a elevação dos picos das montanhas em diferentes escalas. Os processos tectônicos governam a média da espessura da crosta, a variabilidade espacial no soerguimento da rocha e a rigidez da flexura da crosta, que, por seu turno, controla a elevação da cadeia de montanha. Esses autores trabalham com a idéia de que a remoção da rocha pela escavação dos vales pelos rios e geleiras, desencadeia o soerguimento da montanha pelo processo isostático. Dessa forma, as montanhas ganham altura pela própria descida da base causada pela incisão dos processos erosivos, e também pelo soerguimento isostático. Esses autores também argumentam que esses processos controlam entre $21 \mathrm{e}$ $32 \%$ da altura da montanha, o restante é em função dos processos tectônicos e características da crosta.

Como lembram Montgomery \& Greenberg (2000), a altura da montanha é medida verticalmante do topo até o fundo do vale, que deu origem à vertente. Entretanto, ela também pode ser pelo desnível produzido pelo deslocamento de blocos continentais (falhamentos). Sendo assim, uma única montanha pode ter mais de uma altura em função de suas vertentes. Obviamente se escolhe a maior para se estabeler a altura. Gerrard (1990) disserta que, para alguns autores, montanhas altas possuem altitudes acima de 1.500 metros e rele- 
vo relativo de 1.000 metros. Hammond (1954 e 1964) usou o relevo relativo local de $900 \mathrm{~m}$ para separar montanhas altas de montanhas baixas nas Américas do Norte e do Sul. Montanha baixa foi definida por ele como tendo relevo relativo local entre 300 e 900 metros, incluindo os Apalaches, as terras altas da Guiana e as montanhas costeiras do Brasil, situadas na Serra do Mar e na Serra da Mantiqueira. Sendo assim, não existe um consenso na geomorfologia para classificar montanhas altas, médias e baixas.

\subsection{Geoecologia}

Muitos autores que trabalham com geoecologia em regiões de clima temperado, determinam que a linha de neve eterna (snow line) ou o limite até onde a vegetação arbustiva alcança (timberland), indicam o limite de ambiente de montanhas altas, conhecida também como zona alpina. Porém, o limite inferior da zona alpina varia com a latitude e com o clima local (Tabela 1). Também existe uma enorme discrepância entre a linha de neve e o limite da vegetação arbustiva em função do clima e da latitude. A linha de neve pode ainda variar muito em uma mesma montanha, por exemplo, nas vertentes voltadas para o oceano a linha tende a ser mais baixa que na vertente voltada para o interior, isso é mais notório quando o clima do interior é semi-árido. A própria exposição ao Sol influencia diretamente a linha de neve, nas vertentes sombreadas ela tende a ser mais baixa.

No Hemisfério Norte as geleiras são mais freqüentes nas vertentes norte devido ao sombreamento, enquanto no Hemisfério Sul elas aparecem mais comumente nas vertentes sul pelo mesmo motivo. Trabalhos de muitos pesquisadores vêm indicando que a linha de neve está se deslocando para cima em várias montanhas no planeta, devido ao aumento da temperatura global. Isso complica ainda mais este tipo de interpretação e vem influenciando diretamente no derretimento e retração das geleiras alpinas.

Tabela 1: Altitude da linha de neve (zona alpina) em função da latitude.

\begin{tabular}{l|c|c}
\hline \multicolumn{1}{c|}{ Região } & Latitude & $\begin{array}{c}\text { Altitude da } \\
\text { Linha de Neve (m) }\end{array}$ \\
\hline Pólos & $90^{\circ} \mathrm{N}$ e S & Ao nível do mar \\
\hline Groenlândia & $60^{\circ}-85^{\circ} \mathrm{N}$ & 600 \\
\hline Alasca & $58^{\circ}-73^{\circ} \mathrm{N}$ & 700 \\
\hline Montanhas North Cascades & $45^{\circ}-50^{\circ} \mathrm{N}$ & 3.000 \\
\hline Himalaia & $28^{\circ}-38^{\circ} \mathrm{N}$ & 4.800 \\
\hline Andes do Peru & $5^{\circ}-17^{\circ} \mathrm{S}$ & 4.800 \\
\hline Linha do Equador & $0^{\circ}$ & 4.500 \\
\hline
\end{tabular}

Da mesma forma, de acordo com Gerrard (1990), a vegetação arbustiva só cresce até uma determinada altitude e o limite dessa zona (timberland line) difere muito em função da latitude. Também deve ser levado em conta que nas regiões áridas a situação é muito diferente das regiões com outros tipos climáticos, sendo assim, algumas montanhas altas nos trópicos áridos não possuem paisagens de montanhas alpinas, mesmo tendo altitudes de 6.000 metros, como acontece em várias montanhas que se situam dentro do perímetro do Deserto do Atacama, entre elas: Ojos del Salado (6.863 m), Llullaillaco (6.723 m) e Antofalla (6.100 m).

Uma outra questão levantada por Hollermann (1973) e Troll (1973), é que o ambiente alpino pode ter muitas similaridades com o ambiente árido de montanha. Os depósitos de tálus produzidos pela decomposição mecânica das rochas (intemperismo físico) são extensos em ambos os ambientes de montanha, o alpino e o desértico. Os solos também são rasos e pouco desenvolvidos. Os fluxos de degelo em ambientes alpinos e os fluxos torrenciais de chuva nas encostas áridas, produzem perfis de encostas que se assemelham.

Apesar de todas estas críticas serem contundentes, no sentido de colocar a perspectiva geoecológica em dúvida, ela ainda pode ser aplicada localmente, mas seria um grande erro adotá-la como modelo universal.

\subsection{Montanhismo}

Os montanhistas classificam montanhas baixas e altas em função da natureza da atividade que praticam, mas não existe um consenso entre eles. É levada em consideração a altura, ou seja, o desnível vertical entre a base e o topo. Mas existe um grande problema na perspectiva dos montanhistas porque, em geral, eles levam em consideração apenas a parte conhecida na geomorfologia como escarpa (free fall face), que possui declividade acima de $45^{\circ}$. Normalmente eles não consideram a meia encosta, com declividade de até $35^{\circ}$ e nem o "sopé da encosta", onde se deposita o material coluvionar, de acordo com a classificação de Dalrymple et al (1968). Ou seja, na maioria das vezes eles só consideram a escarpa em rocha aflorando. O sentido de "alta montanha", termo utilizado por eles, varia em função das regiões climáticas onde vivem. A maioria considera que montanha alta é aquela que possui altura muito acima da zona alpina (linha de neve), o que acaba gerando mais confusão, como foi exposto anteriormente.

\subsection{Fisiologia Humana}

Uma outra forma possível de classificar montanhas baixas, médias e altas é em função dos efeitos da altitude no organismo humano. Por exemplo, a partir de $2.400 \mathrm{~m}$ de altitude as pessoas já começam a sentir os efeitos da pressão do oxigênio. Os médicos fisiologistas distinguem três zonas de altitude que podem causar problemas: moderada, entre 2.400 e $3.600 \mathrm{~m}$; alta, entre 3.600 e $5.400 \mathrm{~m}$ e extremas, acima de $5.400 \mathrm{~m}$. 
De acordo com os dados apresentados por Stone (1992), exemplificados na Tabela 2, o volume de oxigênio na atmosfera (troposfera) não muda em altitude, os $21 \%$ desse gás permanecem inalterados, do nível do mar a 15.000 metros de altitude. Mas a pressão atmosférica diminui inversamente ao ganho de altitude e isso influencia na pressão do oxigênio. $\mathrm{O}$ oxigênio $\left(\mathrm{O}_{2}\right)$ é inalado para os pulmões de onde ele é passado para a corrente sangüínea, via hemoglobina. Ao nível do mar a hemoglobina (glóbulos vermelhos) pode transportar $19.5 \mathrm{ml}$ de oxigênio em cada $100 \mathrm{ml}$ de sangue; a 3.000 metros de altitude, a mesma quantidade de hemoglobina só consegue transportar $18.5 \mathrm{ml}$ para cada $100 \mathrm{ml}$ de sangue, ou seja, só há $95 \%$ de oxigênio disponível; a 8.000 metros a mesma quantidade de hemaglobina só consegue transportar $8.5 \mathrm{ml}$ em cada $100 \mathrm{ml}$ de sangue.

Para compensar a diminuição na saturação de oxigênio no sangue, o organismo produz mais hemoglobina para poder transportar uma quantidade maior de oxigênio. Dessa forma, o sangue fica mais denso e circula com velocidade menor.

Tabela 2: Disponibilidade de $\mathrm{O}_{2}$ em altitude.

\begin{tabular}{c|c|c|c}
\hline $\begin{array}{c}\text { Altitude } \\
\text { (metros) }\end{array}$ & $\begin{array}{c}\text { Pressão do O2 } \\
\text { (mm/Hg) }\end{array}$ & $\begin{array}{c}\text { Volume de O2 em } \\
\text { 100 ml de sangue }\end{array}$ & $\begin{array}{c}\text { Volume real de } \\
\text { O2 inalado }\end{array}$ \\
\hline 0 & 100 & 19.5 & $100 \%$ \\
\hline 3.000 & 73 & 18.5 & $95 \%$ \\
\hline 6.000 & 40 & 14.5 & $74 \%$ \\
\hline 8.000 & 32 & 8.5 & $43 \%$ \\
\hline 8.800 & 28 & 6.2 & $32 \%$ \\
\hline
\end{tabular}

O cérebro consome cerca de $20 \%$ do oxigênio inalado, portanto, a falta deste gás afeta primeiro essa parte do corpo e depois afeta a parte muscular. Daí a sensação de cansaço causado pelo estresse. Em montanhas de até $3.000 \mathrm{~m}$ de altitude o organismo de uma pessoa saudável não apresenta problemas de grande importância, porque nesse nível o volume de oxigênio disponível é de aproximadamente 95\%.

A partir de 3.000 metros de altitude, um terço das pessoas que sobe com rapidez e sem adequada aclimatação prévia, tem problemas. A $5.000 \mathrm{~m}$ esses problemas se multiplicam. Nesta faixa, começa uma zona realmente perigosa que pode ser fatal para quem não está adequadamente aclimatado e é necessário possuir uma boa forma física para evitá-los ou suportá-los. Os problemas mais comuns são edema pulmonar, edema cerebral, taquicardia, desidratação e alucinações. Tudo isso é popularmente conhecido como "mal de montanha". Entre 3.000 e 6.000 m de altitude, o volume de oxigênio disponível fica entre 95 e $74 \%$ respectivamente ou seja, é muito pouco oxigênio disponível para as atividades físicas intensas.

Depois dos $6.000 \mathrm{~m}$ de altitude começa a chamada "zona da morte", quando o volume de oxigênio disponível é de 74\% e as mortes causadas pelos efeitos da altitude são comuns. A 8.000 mo volume de $\mathrm{O}_{2}$ é de apenas $43 \%$ e no topo do Everest cai para apenas $32 \%$, o que é um volume extremamente reduzido.

Um outro problema é que na medida em que se afasta da linha do equador $\left(0^{\circ}\right.$ de latitude) em direção aos pólos Norte ou Sul ( $90^{\circ}$ de latitude), a pressão do oxigênio muda, ou seja, uma pessoa ao subir uma montanha de 4.000 na Antártica pode sofrer tanto com a altitude quanto uma pessoa que está subindo uma montanha de 6.000 nas latitudes tropicais, isso porque na Linha do Equador o limite da troposfera chega a $15 \mathrm{~km}$ de altitude, enquanto nos pólos o limite fica apenas a $7 \mathrm{~km}$ de altitude. É por isso é que a pressão do oxigênio deve ser relativa nesta classificação e não absoluta.

\section{Metodologia}

Vinte e oito montanhas foram consideradas para servirem como parâmetro para uma proposta de classificação em três classes de altura: baixa, média e alta. A escolha dessas montanhas foi função das características de cada uma, como:

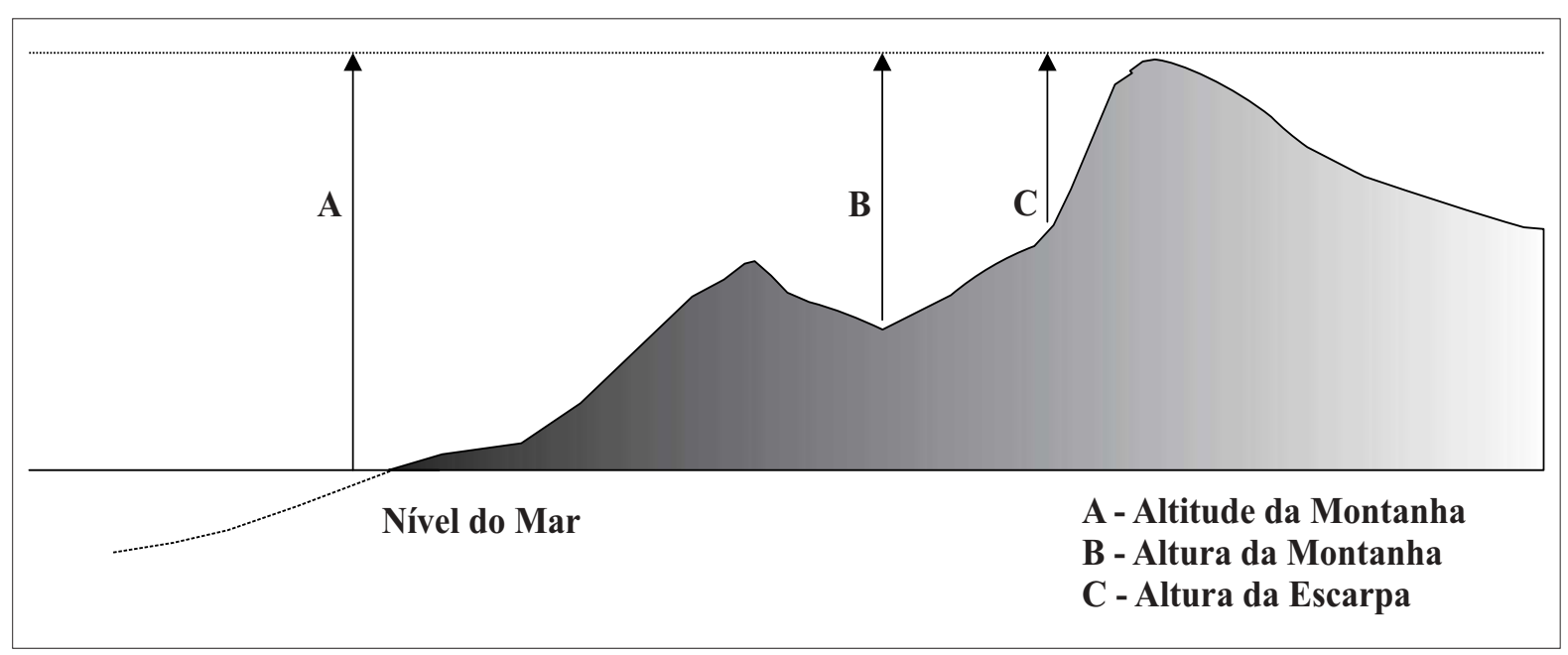

Figura 1: Altura e altitude das montanhas e altura das escarpas, de acordo com o autor. 
gênese, forma, latitude, altitude, representatividade e dados sobre glaciologia e clima. Outro ponto fundamental foi a disponibilidade de cartas e mapas topográficos (ver referências cartográficas), necessários para medir a altura da montanha, ou altura da maior vertente $(\mathrm{H})$, que corresponde à diferença entre a maior e a menor altitude encontrada na vertente, de acordo com Christofoletti (1974), Blong (1975) e Montgomery \& Greeberg (2000). A Figura 1 exemplifica esta metodologia. Outras características morfométricas foram medidas, como comprimento da superfície da maior vertente e o ângulo médio, mas resolveu-se não incluí-las nas tabelas por considerálas irrelevantes. No entanto, esses dados foram utilizados para verificar quais são as maiores escarpas do Brasil (inclinação acima de $45^{\circ}$ e sem cobertura de solo), o que interessa particularmente aos montanhistas que praticam escalada técnica, e que as denominam de "paredão", como disserta Faria (2003 e 2004b).

\section{Análise sobre a altura das montanhas}

Existem diversos tipos de montanhas em função da gênese. As 28 montanhas estudadas abrangem quase todos os tipos existentes, de acordo com a classificação de Fairbridge
(1968). Elas são do tipo: montanhas vulcânicas, montanhas em dobras ou nappe, montanhas em bloco, montanhas em domo, montanhas em soerguimentos erodidos, montanhas em estruturas residuais, montanhas em tectônica policíclica, montanhas formadas por erosão diferencial e montanhas em formas denudacionais policíclicas. Apenas dois tipos de montanhas não foram contemplados, por serem mais raros. A Tabela 3 mostra os resultados obtidos.

Levando em consideração a percepção humana, em se tratando de tamanho/altura e também os aspectos geomorfológicos, classificar montanhas em relação a altura (baixa, média e alta) pode ser útil. Tecnicamente isto se justifica porque as montanhas são definidas em função deste parâmetro, ou seja, altura maior que $300 \mathrm{~m}$ em relação ao relevo médio circundante. Isto quer dizer que deve ser desprezada a altitude e a condição latitude/clima que considera os ambientes alpinos. Sendo assim, é sugerido aqui que montanhas baixas têm altura entre 300 e $1.000 \mathrm{~m}$; as médias ficam entre 1.000 e $3.000 \mathrm{~m}$ e as altas acima de $3.000 \mathrm{~m}$ (Tabela 4). O limite inferior de $3.000 \mathrm{~m}$ para montanhas altas também se justifica porque se a montanha tiver sua base ao nível do mar, ou próxima, significa que a altura e a altitude se nivelam. Nessa faixa já é sentido os efeitos da altitude, como ocorre

Tabela 3: Montanhas altas, médias e baixas.

\begin{tabular}{|c|c|c|c|c|c|c|}
\hline Montanha & País & Coordenadas & $\begin{array}{l}\text { Altitude } \\
\text { máxima }\end{array}$ & $\begin{array}{l}\text { Altitude } \\
\text { mínima }\end{array}$ & Altura & Vertente \\
\hline Dhaulagiri & Nepal & $28^{\circ} 41^{\prime} \mathrm{N}-83^{\circ} 30^{\prime} \mathrm{E}$ & 8.167 & 2.500 & 5.667 & $\mathrm{SE}$ \\
\hline McKinley & Alasca (EUA) & $63^{\circ} 04^{\prime} \mathrm{N}-151^{\circ} 00^{\prime} \mathrm{W}$ & 6.194 & 1.450 & 4.744 & $\mathrm{~N}$ \\
\hline Nanga Parbat & Paquistão & $35^{\circ} 05^{\prime} \mathrm{N}-75^{\circ} 10^{\prime} \mathrm{E}$ & 8.126 & 3.500 & 4.626 & SE \\
\hline Annapurna I & Nepal & $28^{\circ} 37^{\prime} \mathrm{N}-83^{\circ} 50^{\prime} \mathrm{E}$ & 8.091 & 3.500 & 4.591 & NW \\
\hline Huscaran & Peru & $9^{\circ} 06^{\prime} \mathrm{S}-77^{\circ} 35^{\prime} \mathrm{W}$ & 6.768 & 2.500 & 4.268 & $\mathrm{~S}$ \\
\hline Mauna Kea & Havai (EUA) & $19^{\circ} 50^{\prime} \mathrm{N}-155^{\circ} 30^{\prime} \mathrm{W}$ & 4.205 & N.mar & 4.205 & $\mathrm{E}$ \\
\hline Mont Logan & Canadá & $48^{\circ} 32^{\prime} \mathrm{N}-120^{\circ} 57^{\prime} \mathrm{W}$ & 5.959 & 1.829 & 4.130 & $\mathrm{~S}$ \\
\hline Wrangell & Alasca (EUA) & $62^{\circ} 00^{\prime} \mathrm{N}-144^{\circ} 15^{\prime} \mathrm{W}$ & 4.317 & 290 & 4.027 & $\mathrm{~S}$ \\
\hline Huandoy Oeste & Peru & $9^{\circ} 03^{\prime} \mathrm{S}-77^{\circ} 40^{\prime} \mathrm{W}$ & 6.356 & 2.500 & 3.856 & $\mathrm{~S}$ \\
\hline Mont Blanc & França/Itália & $45^{\circ} 50^{\prime} \mathrm{N}-6^{\circ} 52^{\prime} \mathrm{E}$ & 4.808 & 1.003 & 3.805 & $\mathrm{~N}$ \\
\hline Ever est & Nepal/China & $27^{\circ} 52^{\prime} \mathrm{N}-86^{\circ} 55^{\prime} \mathrm{E}$ & 8.850 & 5.650 & 3.200 & $E$ \\
\hline Ranier & EUA & $46^{\circ} 52^{\prime} \mathrm{N}-121^{\circ} 45^{\prime} \mathrm{W}$ & 4.392 & 1.192 & 3.200 & $\mathrm{~W}$ \\
\hline K2 & Paquistão/Ch & $35^{\circ} 50^{\prime} \mathrm{N}-76^{\circ} 30^{\prime} \mathrm{E}$ & 8.611 & 5.500 & 3.111 & SE \\
\hline Aiguille du Midi & França & $45^{\circ} 57^{\prime} \mathrm{N}-6^{\circ} 53^{\prime} \mathrm{E}$ & 3.842 & 1.020 & 2.822 & NW \\
\hline Fitz Roy & Argentina & $49^{\circ} 15^{\prime} \mathrm{N}-73^{\circ} 04^{\prime} \mathrm{W}$ & 3.441 & 700 & 2.741 & NW \\
\hline Dent de Géant & França/Itália & $45^{\circ} 50^{\prime} \mathrm{N}-6^{\circ} 55^{\prime} \mathrm{E}$ & 4.013 & 1.500 & 2.513 & SW \\
\hline Torre Sul & Chile & $50^{\circ} 58^{\prime} \mathrm{S}-73^{\circ} 00^{\prime} \mathrm{W}$ & 2.850 & 500 & 2.350 & $\mathrm{E}$ \\
\hline Pico dos Marins & Brasil & $24^{\circ} 30^{\prime} \mathrm{S}-46^{\circ} 15^{\prime} \mathrm{W}$ & 2.422 & 500 & 1.922 & $\mathrm{~S}$ \\
\hline Pico Paraná & Brasil & $25^{\circ} 05^{\prime} \mathrm{S}-49^{\circ} 00^{\prime} \mathrm{W}$ & 1.922 & N. mar & 1.922 & $\mathrm{~S}$ \\
\hline Rundle & Canadá & $51^{\circ} 07^{\prime} \mathrm{N}-116^{\circ} 30^{\prime} \mathrm{W}$ & 2.949 & 1.395 & 1.554 & $\mathrm{NE}$ \\
\hline Half Dome & EUA & $37^{\circ} 45^{\prime} \mathrm{N}-119^{\circ} 35^{\prime} \mathrm{W}$ & 2.696 & 1.248 & 1.448 & NW \\
\hline Chuar Butte & EUA & $36^{\circ} 11^{\prime} \mathrm{N}-111^{\circ} 49^{\prime} \mathrm{W}$ & 1.949 & 730 & 1.219 & $\mathrm{E}$ \\
\hline Table Mountain & África do Sul & $33^{\circ} 95^{\prime} \mathrm{S}-18^{\circ} 41^{\prime} \mathrm{W}$ & 1.087 & N. mar & 1.087 & $\mathrm{~S}$ \\
\hline Pico da Bandeira & Brasil & & 2.890 & 1.890 & 1.000 & $\mathrm{NE}$ \\
\hline Bou Khadra & Algéria & $36^{\circ} 18^{\prime} \mathrm{N}-05^{\circ} 15^{\prime} \mathrm{E}$ & 1.483 & 750 & 733 & SW \\
\hline Corcovado & Brasil & & 704 & N.mar & 704 & $\mathrm{~S}$ \\
\hline Le Bambois & Suiça & $47^{\circ} 25^{\prime} \mathrm{N}-07^{\circ} 20^{\prime} \mathrm{E}$ & 840 & 424 & 416 & $\mathrm{~S}$ \\
\hline Pão de Açúcar & Brasil & & 392 & N. mar & 395 & $\mathrm{~S}$ \\
\hline
\end{tabular}


Tabela 4: Tipos de classificação de montanhas baixas, médias e altas.

\begin{tabular}{l|r|r|r}
\hline \multicolumn{1}{c|}{ Montanhas } & \multicolumn{1}{c|}{ Baixa } & Média & Alta \\
\hline Geomorfologia & $<1.000 \mathrm{~m}-$ altura $^{(1)}$ & - & $>1.000 \mathrm{~m}-$ altura $^{(1)}$ \\
\hline Geoecologia & - & - & Acima da linha de neve \\
\hline Montanhismo & - & - & Acima da linha de neve \\
\hline Fisiologia & $<2.400 \mathrm{~m}-$ altitude $^{(2)}$ & $2.400-3.600 \mathrm{~m}^{(3)}$ & $>3.600 \mathrm{~m}-$ altitude $^{(3)}$ \\
\hline Proposta & $<1.000 \mathrm{~m}-$ altura $^{(1)}$ & $1.000-3.000 \mathrm{~m}^{(1)}$ & $>3.000 \mathrm{~m}-$ altur a $^{(1)}$ \\
\hline
\end{tabular}

(1) Relativo à altura local, entre a base e o topo.

(2) A linha de neve (zona alpina) oscila em função da latitude.

${ }^{(3)}$ Determinado pela altitude.

em muitas montanhas altas que ficam em zonas litorâneas, por exemplo, o Mauna Kea, com altitude e altura de 4.205 m, porque a menor altitude da maior vertente se situa ao nível do mar. Existem ainda muitas outras montanhas nesta condição, a maioria é formada por vulcões.

Estes dados servem para exemplificar que as maiores altitudes não importam na determinação das montanhas altas, como pode ser visto na comparação feita na Figura 2. A gênese é o fator mais importante, ou seja, as montanhas mais altas são formadas por orogênese e por vulcanismo. Existe um número enorme de montanhas com altura entre 3.000 e 5.700 metros, ou seja, montanhas altas. Somente na cadeia do Himalaia encontra-se um grande número e ainda tem muitas outras distribuídas em várias outras cadeias de montanhas na Ásia, na Europa, na América do Norte, na América do Sul, na América Central, na África e na Oceania, mas podem ser também vulcões isolados, originados em pontos quentes (hot spot). Vale salientar que algumas das montanhas mais altas se encontram fora da Cadeia do Himalaia, como o Monte McKinley, o Nevado Huascaran, o Monte Wrangell e o Vulcão Mauna Kea, entre outras.
De acordo com esta classificação, as maiores montanhas brasileiras em área continental têm altura média. As mais altas têm aproximadamente 1.800 metros e vertentes com até $4.000 \mathrm{~m}$ de extensão. Elas se encontram na Serra do Mar (RJ e PR), na Serra da Mantiqueira (SP, MG e RJ) e na Serra do Imeri (AM). Nenhuma montanha brasileira alcança os 3.000 $m$ de altitude, a mais elevada continua sendo o Pico da Neblina (2.994 m), de acordo com os dados divulgados pelo Instituto Brasileiro de Geografia e Estatística e Instituto Militar de Engenharia.

\subsection{As maiores escarpas}

Curiosamente, as maiores escarpas ("paredões" com mais de $45^{\circ}$ ) no Brasil têm altura entre 600 e 800 m e elas se situam ou na borda das serras ou nas maiores vertentes de certas montanhas. Praticamente todas se formaram no desnível produzido pelo deslocamento vertical de blocos (espelho de falha). A área de maior ocorrência fica na Serra dos Órgãos, nome regional de um trecho da Serra do Mar, no Rio de Janeiro. Destacam-se: o Pico Maior de Friburgo (2.350 m), com altura da escarpa de aproximadamente $600 \mathrm{~m}$ - essa montanha também é o ponto culminante de toda a Serra do Mar; a Maria Comprida (1.926 m); o Morro dos Cabritos (1.800 m); o Escalavrado (1.420 m); a Pedra da Anta (2.000 m) e o Garrafão

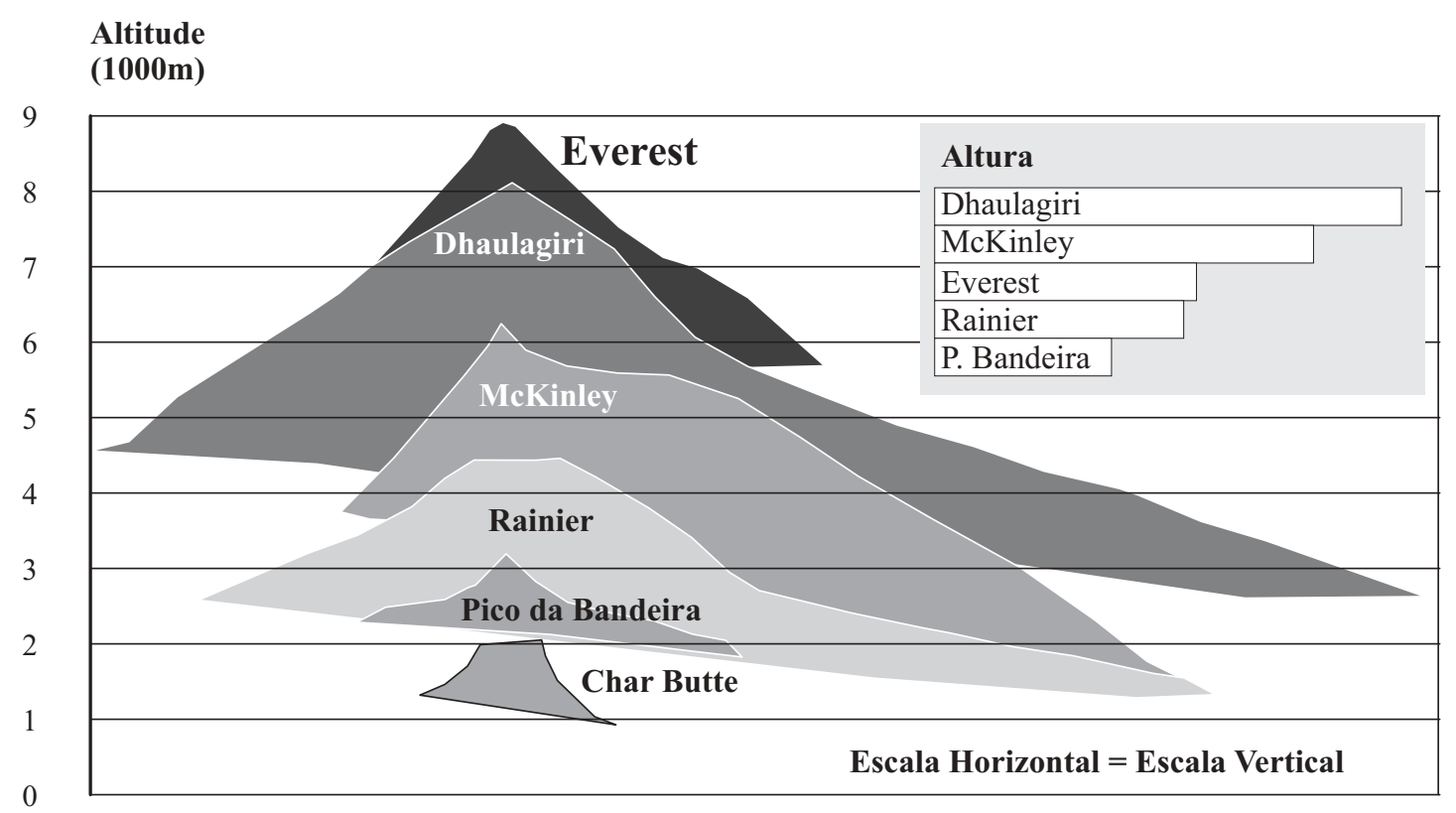

Figura 2: Comparação entre os perfis topográficos de algumas montanhas. 
(2.070 m), entre diversas outras montanhas. Em Minas Gerais se destaca a Pedra Riscada $(1.480 \mathrm{~m})$, situada no NE do estado $\left(41^{\circ} 15^{\prime} \mathrm{W}-18^{\circ} 30^{\prime} \mathrm{S}\right)$ com altura da escarpa estimada por montanhistas em mais de $800 \mathrm{~m}$, como destaca Latorre \& Azevedo (2002) e Bortolusso (2002). Segundo essas informações, essa escarpa pode ser a maior no Brasil.

De acordo com Faria (em publicação), montanhas de mesma origem geológica no mundo inteiro, produzidas por movimentos epirogenéticos em zonas de rifteamento originadas em antigas áreas de divergência de placas, também possuem escarpas com alturas similares às encontradas no Brasil, como ocorre nos países que circundam o Mar Vermelho (Sudão, Eritréia e Arábia Saudita), Oeste da Índia, Oeste da Namíbia, Sul da África do Sul, Oeste de Madagascar e Leste e Sudeste da Austrália. As maiores escarpas produzidas por movimentos epirogenéticos possuem altura entre 1.200 e $1.400 \mathrm{~m}$ em montanhas com altitudes de até $3.000 \mathrm{~m}$. Elas se situam em áreas onde ocorreu forte glaciação no Pleistoceno e ainda estão sob ação de geleiras, como ocorre na Ilha de Baffin (Norte do Canadá), no Oeste da Antártica, Oeste e Leste da Groenlândia e Oeste da Noruega. Seria este o limite de altura das escarpas das montanhas produzidas por epirogênese?

\subsection{Outras considerações}

Tem sido dito pela mídia que a Ilha Havaí é a maior montanha da Terra, porque a base se situa a 5.000 de profundidade, o que forma um desnível de aproximadamente $9.200 \mathrm{~m}$. Entretanto, a inclinação das vertentes submersas é baixa, em torno de $10^{\circ}$, em função de ser uma área de deposição submersa em meio hídrico. A ilha se parece mais com um platô vulcânico do que a uma montanha, e sobre ele formaram-se dois grandes vulcões, além de montanhas menores. Os mapas, especialmente os de pequena escala, trabalham com escalas verticais exageradas e isso pode promover interpretações erradas. De qualquer forma, um dos parâmetros para definir montanha é a declividade acentuada das vertentes, resta saber o que significa inclinação "acentuada".

Os dados obtidos mostram que a afirmação de montanhistas de que o Monte McKinley ou Denali, é a maior montanha terrestre em área continental não é correta, a maior pode ser o Dhaulagiri $(8.167 \mathrm{~m})$, com altura aproximada de $5.700 \mathrm{~m}$. O Everest $(8.850 \mathrm{~m})$, obviamente, continua sendo a de maior altitude.

\section{Conclusão}

Este trabalho torna-se útil porque este tipo de discussão faz parte de um importante referencial da geomorfologia, mas visa ainda dar uma contribuição no que refere à classificação das montanhas em função da altura, porque, de acordo com a bibliografia consultada, ainda carece de discussões específicas.

Nota: O autor é montanhista há 25 anos, tendo escalado e feito observações em muitas montanhas nos Andes (Chile,
Argentina, Peru e na região da Patagônia), nos Alpes (Suíça, França e Itália), nos Atlas (Marrocos), nas Montanhas Rochosas (Canadá e EUA), no North Cascades (EUA e Canadá), nos Apalaches (EUA), na Cadeia do Alasca (EUA) e em boa parte do território brasileiro.

\section{Referências Bibliográficas}

Bates, R. L \& Jackson, J. A. (1984). Dictionary of Geological Terms. New York. Anchor Books. 571p.

Blocklehurst, S. H. \& Whipple, K. X. (2004). Hypsometry of glaciated landscapes. Earth Processes and Landforms, 29: 907-926.

Blong, R. J. (1975). Hillslope morphometry and classification: a New Zealand example. Zeitschrift fur Geomorphologie, 19 (4): 405-429.

Bortolusso, M. (2002). Pedra Riscada: A conquista da maior via de escalada do Brasil. Adventure, ano IV, n. 40: 42-55.

Christofoletti, A. (1974). Geomorfologia. São Paulo. Edgard Blücher, $188 \mathrm{p}$

Cruden, D. M. \& HU, X. Q. (1999). The shapes of some mountain peaks in the Canadian Rockies. Earth Surface Processes and Landform, 24: 1229-1241.

Dalrymple, J. B.; Blong, R. J. \& Conacher, A. J. (1968). A hyphotetical nine unit land surface model. Zeitschrift fur Geomorphologie, 12 (1): 60-76.

Fairbrigde, R. W. (1968). Mountain and Lilly terrain, mountain systems; mountain types. In: R. W. Fairbridge (ed.), Encyclopedia of Geomorphology. New York, Reinhold, 745-761.

Faria, A. P. (em publicação). Montanhas. Faria, A. P. (2003). A era das super vias no Brasil. Mountain Voices N. 72.

Faria, A. P. (2004a). A Formação do Maciço da Tijuca. In: F. Daflon \& D. Queiroz (Edit.), Guia de Escaladas e Caminhadas da Floresta da Tijuca. Rio de Janeiro, Cia da Escalada, 297 p.

Faria, A. P. (2004b). O céu é o limite. Headwall, n. 9: 7-10.

Faria, A. P. (2005). Nomes das montanhas: uma guerra de culturas. Geografia, v. 30, n. 2: 390-397.

Gerrard. J. (1990). Mountain Environments. London. Belhaven Press. 317 p.

Guerra, A. J. T (1993). Dicionário GeológicoGeomorfológico. Rio de Janeiro, Bertrand.

Hammond, E. H. (1954). Small-scale continental landform maps. Annals of Assoc. American Geographers, 44:33-42.

Hammond, E. H. (1964). Classes of land - surface form in the forty eight states, USA. Annals of Assoc. American Geographers, 54.

Hollerman, P. (1973). Some reflections on the nature of high mountains with special reference to the western United States. Artic and Alpine Research, 5 (3):149-160. 
King, L. C. (1967). The Morphology of the Earth. Edinburgh. Oliver and Boyd.

Latorre, P. \& Azevedo, E. V. (2002). Pedra Riscada: a conquista do maior monolito do país. Universo Vertical, n. 1 (abril/maio); 24-37.

Montgomery, D. R. \& Greenberg, H. M. (2000). Local relief and the height of Mount Olympus. Earth Surface Processes and Landforms, 25: 385-396.

Price, L. W. (1991). Mountains and Man. University of California Press, Berkeley.

Stone. P. B. (1992). State of the World's Mountains: a global report. New Jersey. Zed Books Ltd. 393 p.

Troll, C. (1973). High mountains belts between the polar caps and the equator: their definition and lower limit. Artic and Alpine Research, 5 (3):19-28.

\section{Referências cartográficas}

Discover Nepal (1986). Round Annapurna. Topographic map 1.150.000. IBGE (1972). Carta topográfica de Itaipava 1:50.000.

IBGE (1972). Carta topográfica de Petrópolis 1:50.000.

IBGE (1974). Carta topográfica de Teresópolis 1:50.000.

IBGE(1981).Carta topográfica de Nova Friburgo 1:50.000.
IBGE (1986). Carta topográfica de Manhumirim 1:50.000. IBGE (1988). Carta topográfica de Passa-Quatro 1:50.000. Institut Géographique National (1956). Atlas des Formes du Relief. Paris, 179 p.

Institut Géographique National (1989). St. GervaisMassive du Mont Blanc. France, carte 1:25.000.

Instituto Geográfico Nacional (1988). Cordillera Blanca. Peru, carta nacional 1:100.000.

Instituto Militar Geográfico de Chile (1980). Parque Nacional Torres del Paines. Mapa topográfico 1:100.000.

National Geographic Society (1988). Mount Everest topographic map 1:50.000.

Serviços Aerofotogramétricos Cruzeiro do Sul (1961). Cartas topográficas do Estado da Guanabara, escala 1:5.000.

U.S. Geological Survey (1989). Mount Rainier. Topographic map 1:50.000.

U.S. Geological Survey (1995). Mauna Kea. Topographic map 1:50.000.

U.S. Geological Survey (1996). Wrangell-Saint Elias National Park. Topographic map 1:50.000.

U.S. Geological Survey (1999). Denali National Park. Topographic map 1:50.000.

U.S. Geological Survey (2001). Grand Canyon National Park. Topographic map 1:40.000. 